\title{
In Defense of Critical Democratic Pedagogy
}

\author{
Tracey Isaacs
}

\author{
$\mathrm{PhD}$, Senior Researcher, International Society of Philosophy and Cosmology \\ (Stellenbosch, South Africa) \\ E-mail: tray_236@hotmail.com
}

\begin{abstract}
A powerful positivist and neoliberal ideology in education masquerades more or less unharmed as the meritocratic myth promised under the cloak of democracy. Yet some students and teachers are beginning to interrogate the success-only orientations of neoliberalism in the face of crumbling school systems where many students fail. These students and teachers are not oblivious to the stark realities that characterize their daily existence, as they live under a dark cloud of mass unemployment and inequality where many struggle to "succeed". Additionally, trained consciousness reveals the pockmarked version of democracy that admits only a few and is attendant with an authoritarian, disciplinary practice that breeds resistance towards education rather than the envisioned freedom it is purported to usher in. These inconsistent positions as an experience of education, by especially marginal students, is intensifying within a neoliberal discourse and invites the intense consideration of the place of critical democratic pedagogy as a more appropriate approach toward democratic teaching and learning practices. Within this context, I explore the theoretical and practical dimensions of critical pedagogy to provide an expanded view of teaching and learning in post-democratic South African education.
\end{abstract}

Keywords: critical pedagogy, democracy, freedom, neoliberal, positivist, meritocracy, authoritarian

Received January 30, 2018; accepted March 1, 2018

Future Human Image, Volume 9, 2018:

DOI: $10.29202 / \mathrm{fhi} / 9 / 3$

\section{Towards a critical pedagogy in South African education?}

To consider schooling as an authoritarian, anti-democratic, disciplinary practice is tantamount to characterizing students and teachers in the theoretical model of oppressed/ oppressor as argued by Freire (2005: 20). While pedagogy can be defined as leading children towards positive transformation (intellectually, affectively, and spiritually); in marked contrast authoritarian and controlling pedagogy victimizes, and is dehumanizing to students (Freire 2005: 44). In this context, the teacher oppresses the student through alienation and by silencing student voice by virtue of the asymmetrical power relations that exist in the teacher-student hierarchy (Freire 2005: 44; 88). This cultural and political hierarchy has been normalized by the state, the institution (school, university) and the teacher through non-negotiated policy and practices to ostensibly provide the students, as democratic citizens, with an assurance of their

(C) Isaacs, Tracey, 2018 
rights and to maintain order and efficiency. However, rights in the absence of the necessary intellectual sophistication to appreciate the attendant responsibilities and obligations required of the one accorded those rights, could be considered a futile attempt at democratic enactment. To this Freire advocates that students (as the oppressed) must gain consciousness of their vulnerability and need to be weaned off of their dependence on the authoritarian teacher in an effort to be truly free and liberated (Freire 2005: 95).

He suggests that to employ reason fruitfully empowers students to reflect and criticize anti-democratic conventions; and this in turn creates an avenue to change undemocratic practices (Freire, 2005: 97). In Freire's dialogical, co-intentional educational model, teachers and students are co-equal subjects in the task of unveiling reality, knowing it critically and recreating it as a participatory, committed and involved practice. Freire sharply contrasts the democratic personas and activities as described above to the management and manipulation of a controlling pedagogy where the teacher is: generally narrative; content is "lifeless and petrified"; teaching modalities are predictable and knowledge is compartmentalized and alien to the existential experience of students (Freire, 2005: 72). Furthermore, this paternalistic approach to education develops students as listening objects who suffer from "narration sickness"; and who un-creatively record, memorize, and repeat knowledge as stored deposits without making real meaning (Freire, 2005: 72).

According to Freire, this misguided system of education forestalls possibilities for knowledge invention and reinvention; as well as short circuiting the restless, impatient yet hopeful inquiry and curiosity towards the world and others that consciousness-raising pedagogy promotes (Freire, 2005: 18;72). The former mentioned banking pedagogy entrenches the classist, sexist, hierarchical nature of schooling premised on an ideology of oppression where the teacher strives to dominate and control student thinking and actions. As an alternative, Freire considers problem-posing pedagogy as a more equitable educational response that positions both educational agents in the classroom as operating simultaneously as both student and teacher, which is to mean the reinvention of teacher and student roles to the point where the traditional hierarchy is subverted (Freire, 2005: 79). In this more democratic and egalitarian classroom, power is negotiated and the student is positioned both as student and teacher by virtue of the fact that we all have lived experiences to share and to know, and at the same time have the potential for transforming ourselves and society. Yet, by the same token teacher roles vacillate between being the teacher and the student as she (the teacher) is constantly learning and relearning through continuous engagement with students. Despite the fact that we present critical pedagogy, as advanced by Freire as an alternative educational approach; in the South African context critical pedagogy could be thought of as an academic outcast, albeit that it emerges noticeably in the vocabulary of the official curriculum. With that in mind, the upcoming section will attempt to illuminate the position of critical pedagogy within the discourse of curriculum evolution pre- and post-democracy.

To begin with, curriculum reconstitution in South African education is typified by an aggressive stance away from Christian National Education (CNE) and Fundamental Pedagogics (FP) reminiscent of the old apartheid state's response to education provisioning. Secondly, Outcomes-Based Education and its accompanying curriculum, Curriculum 2005 (OBE/C2005), which was implemented post-democracy was celebrated as a welcome alternative to CNE/ FP. And subsequently, further curriculum revisions have culminated in National Curriculum Statement and Curriculum and Assessment Policy Statements NCS/CAPS. Historically, CNE and FP were the legislative devices used by the apartheid government to exercise power and 
authority in education. On the one hand CNE was premised on Calvinist, racist policies that unite church and state, and that place God (thereafter the church, state, family, school etc.) at the top of a hierarchy to instill moral and legal supremacy (Eshak, 1987). And on the other hand, FP was to be recognized as a value-free, "scientific" approach to the only true education under apartheid and the only means by which education could be understood (Eshak, 1987). Thus, unsurprisingly, the notion of authority is borne out in the power to enforce obedience; moral supremacy; the power to influence conduct, the fact that titles and designations give the holder the authority to be believed; and that the title holder is an expert in any question asked (Eshak, 1987). Consequently, it could easily be argued that FP subscribes to a functionalist paradigm as its avowed allegiance to discipline, control and an authoritarian approach to education is visible in its belief in objectivity, and the understanding of social reality through observation without direct participation in the process (Naicker, 2000: 6). Furthermore, the functionalist claim to neutrality gives an impression that the researcher's assessments are a-political and that it is possible to align human affairs to the natural world where relationships can be identified, studied and measured (Burrel \& Morgan, 1979:26). Since the majority of Higher Education Institutions (HEIs) in South Africa subscribed to FP as the only way to study education, a further derivative of FP, Pedagogics influenced a great number of educators as university and college curricula embraced the tenets of this "science" (Naicker, 2000: 8). And whereas:

Fundamental Pedagogic interpretations of learning as being the process of enculturing children to the adult world in a moralistic enactment of principles of Christian national education (CNE), the goals of the former apartheid state (Samuel, 2002: 402);

$\mathrm{OBE} / \mathrm{C} 2005$ was seen as the educational approach and curriculum policy that fore grounded education in post-apartheid South Africa, portrayed as a planned process and strategy of curriculum change underpinned by elements of redress, access, equity and development (Chisholm, 2001: 9). To achieve these targets, C2005 employed methodologies used in progressive pedagogy such as learner centeredness, teachers as facilitators, relevance, contextualized knowledge and cooperative learning (Chisholm, 2001: 9-10). In this way C2005 broke with the racist, authoritarian, rote learning of FP and Pedagogics; and was intended to promote egalitarianism and critical thinking. What is more, C2005 was participatory and inclusive as it saw teachers as curriculum planners, while it endorsed community participation.

And thirdly, still further curriculum review and reform of Revised National Curriculum Statement (RNCS 2004) due to the challenges inherent in OBE/C2005; was done with the following results in mind: that the curriculum be more accessible to teachers; for the mapping of assessment standards; to bring about changes in curriculum terminology, to facilitate the reduction of learning areas; and lastly for the development and distribution of textbooks (DHET, 2011). In other words, the revision of the National Curriculum Statement (NCS) resulted in CAPS, which demarcates what each teacher in every subject should teach, when to teach it, and how to do the accompanying assessments. What follows immediately below as the principles favored in the National Curriculum Statement (NCS):

social transformation; active and critical thinking; high knowledge and high skills; progression; human rights, valuing indigenous knowledge system; credibility; quality and efficiency; and providing an education that is comparable in quality, breadth and depth to those of other countries (DoE, 2011). 
With the above understanding, as a whole in South Africa, curriculum approaches preand post democracy have swung from being functionalist, moralistic and teacher-centered to interpretivist, humane and child-centered; and now it may arguably be considered progressive (embracing critical theory such as social transformation and critical thinking, as well as epistemological diversity), yet it has some frightening neo-liberal overtures (competition, quality, efficiency) too. However, curriculum plans conceal far more in ideology than they might reveal on the functionalist level, as already indicated above: two incompatible discourses run concurrently through the NCS/CAPS, so in the upcoming section I endeavour to problematize the neoliberal discourse in the curriculum statement as it severely compromises the best attempts at fostering a critical democratic pedagogy.

\section{Neoliberal threats to education}

Kincheloe, a respected scholar in critical pedagogy, avers that public education is facing perilous times when a neoliberal ideology permeates education to the degree that political elites determine that education systems are failing, and are too expensive because schools cannot deliver satisfying results (read as return on investment) (Kincheloe \& Steinberg, 2011: 1-2). Thus national governments engage in an exercise of public embarrassment by publishing test results and by punishing poor schools for underachievement, resulting in a winners/losers mentality to pervade schooling and that secretly justifies the value in privatizing schools -supposedly to enhance performance and success (Kincheloe \& Steinberg, 2011: 2). Kincheloe admonishes us to look behind the words of curriculum statements and expose the ideological assumptions inherent therein to detect how unequal power relations are protected and how oppression takes place through the shaping of a particular consciousness (Kincheloe \& Steinberg, 2011: 3). The salient question he highlights is: how is privatized power able to creep into the curriculum design of democratic governments and by extension, why are governments slow to defend freedom and democracy, especially in the case of non-elite students? The implications of educational inequality based on socio-economic class translates into a case where educational policies favor elite classes as they are privileged to gain better access to scientific, technological information and better professions (Kincheloe \& Steinberg, 2011: 2). However, how do all these statements connect with teacher/student authority in classrooms? Neoliberal market dictates regulate commercial markets; manipulate public opinion; promote competition; individualism and consumption; at the same time as they control information and knowledge which affects our perception of the world (Kincheloe \& Steinberg, 2011: 2). And according to Kincheloe and Steinberg, this coincides perfectly with the deskilled, minimally educated teacher who understands her job in the light of controlling students to behave, and think in the ways acceptable and prescribed in official state and school policy (Kincheloe \& Steinberg, 2011: 8). In this way, teachers act as functionaries, carrying out a neoliberal agenda to direct student consciousness through information and knowledge (Kincheloe \& Steinberg, 2011: 8). When in contrast, teachers concerned with critical democratic pedagogy accept a counter hegemonic stance that conveys alternative messages to students, empowering them to challenge corporate control and other anti-democratic practices (Kincheloe \& Steinberg, 2011: 9). Thus, a neoliberal stronghold on education is an affront to democracy as it serves to control and manipulate teachers and students by regulating subject matter of schools and classroom interaction (Kincheloe \& Steinberg, 2011: 10). And while the neoliberal model aims to have power over teachers' work and academic freedom, it concurrently also trains 
students to follow directions, respect authority and ask fewer significant, (critical) questions that challenge the status quo (Kincheloe \& Steinberg, 2011 10). Consequently, critical (antipositivist, alternative) knowledge is minimized or trivialized and knowledge is used as a tool of control in terms of ability and competency testing for teachers, and more especially for students. Moreover, Kincheloe exposes the arrogance of neoliberal ideology in education that tries to quantify the realities of everyday classroom life as he invites us to see the experimental model of teaching based on teacher/student prerogative and innovation, which could be contrasted against the over-determined tests that do not evaluate higher order or critical thinking, or that constructs compelling interpretations of reality (Kincheloe \& Steinberg, 2011: 12). In this way qualitative insight from students and teachers replaces the restrictive forms of authoritarian and anti-democratic control of traditional classroom routines (Kincheloe \& Steinberg, 2011: 13). Now that I have considered how the neoliberal discourse shapes institutional and teacher/ student agency with regards to power, I turn to communicative and pedagogic interactions that promote a dialogical approach to teaching.

\section{Negotiating authority in critical pedagogy}

Shor (1996) presents a model of what a critical democratic classroom might look like when he tackles themes such as power-sharing, shared authority, co-governance and curriculum negotiation with his students in an under-resourced community college. He draws on the concept advanced by Kreisenberg (1992) and Holloway (2003) of "power with" and "power over" where the latter is seen as an alienating and disaffected practice separating the agent from her action (the thinker from her thinking); and where two rival camps compete for power (student and teacher, worker and owner, non-elite and elite) (Kreisenberg, 1992; Holloway, 2003:13). To this, Shor invites alternative pedagogy, critical teaching and experimental practice in his discourse on establishing a speech community in his classroom "to test civic values, critical pedagogy, as well as to challenge social forces pushing dehumanized thought and feeling" (Shor, 1996: 2). He problematizes technical rationality premised on the certitude of facts and dislodges positivist thinking by appealing to thinking that relies on unpredictability, the unknown and "untested feasibility" (Freire, 2005: 113) where power operates "at the margins and in the cracks of the established order"; and more importantly the nurturing of the kind of creative thinking that opens sites where teachers test the limits by "practicing theory and theorizing practice" (Shor, 1996: 3). Practically this was revealed in his analysis of classroom seating preferences as a significant bodily (spatial) text revealing the (unseen and invisible) power relations embedded in schooling; or the ideology of classroom furniture where student chairs for example, indicate a depressant environmental message to students that the institution has no respect for them (Shor, 1996: 4). Shor's analysis of the ideological and environmental factors as well as bodily practices (hand raising, turn taking, etc.) resulted in his interpretation that these factors wordlessly speak to students and mirror the muted messages about the quality of learning; the limited impact of their degree programs; and the control of a "curriculum that barks rules and bellows facts" (Shor, 1996: 11). It is therefore small coincidence that schooling under such conditions resonates closely with a sense and ideology that students are disciplined into a status quo of inequality ("power over" of the institution and teachers), and that it delivers a pedagogic outcome of "uncritical, anti-dialogic silences" on the part of students (Shor, 1996: 11). Precisely because of the anti-democratic nature of curricular and classroom design, Shor set out to dislodge and challenge the architecture of control that 
becomes part of the unquestioned, normative routines of schooling (Shor, 1996: 11). To shatter the anti-democratic nature of classroom hierarchies, he relied on a dialogical approach of negotiated meanings by engaging students to find out the purposes of them selecting the course; their expectations of the course; and their suggestions in making education work better for them (Shor, 1996: 35). In so doing, students were engaged as reflective constituents who contribute to the generative themes emerging from their suggestions, experiences, conditions and expressions (Shor, 1996: 35). Shor describes this pedagogic device as a literate social performance in an alternative and experimental approach to education set in a meaningful context, enacted in a language students possess, cast in a negotiated process, which encourages the questioning of assumptions in order to imagine alternatives to the status quo (Shor, 1996:40). The anti-authoritarian teacher in the above pedagogic encounter is characterized and defined as "frontloading student discourse and backloading teacher commentary" which already signifies a rupture of the traditional teacher role in "banking pedagogy". In marked contrast, the critically democratic teacher considers how to carefully discipline herself so as to follow rather than discipline students in a pre-emptive lecture (predominantly teacher-talk) premised on control and certainty (Shor, 1996: 41). Contrary to what one might imagine in a pedagogy of negotiated power, the teacher's authority does not completely dissolve but enters dialogically according to the shape of the students' discourse, requiring participants (students and teachers) to simultaneously lead and follow (Shor, 1996: 41). Shor therefore understands this complex process to proceed successfully on condition that the teacher assumes an interrogative rather than a declarative posture (Shor, 1996: 42). Consequently, a pedagogy of questions as proposed above allows students sufficient time to reason and speak up; and the use of generative themes sets priorities that open up avenues for constructing student discourse related to the syllabus, their intellectual lives and their social reality and concerns. To be sure, a critical democratic pedagogy as proposed by Shor should not be confused with a permissive pedagogy which allows students to do whatever they want during class time, instead it is suggested as an alternative pedagogy focused on negotiating the curriculum and classroom practice through critical thinking and critical literacy practice in an educational model of cogovernance and power-sharing (Shor, 1996: 48).

Thus far, I have attempted to present an understanding of how the potentials of critical pedagogy have been explored in a particular college program in an effort to develop a more lucid picture of what a critical democratic classroom might look like. What follows immediately below are theoretical positions that reinforce anti-democratic, monologic pedagogic interaction, as well as the classroom practices that provide a lens to observe how critical democratic pedagogy may (or may not) be conceived.

\section{The role of institutional identities in critical democratic pedagogy}

Pretorius (2003) suggests that Higher Education Institutions (HEIs) can be characterized under five structural identities; therefore different structural arrangements produce different approaches to academic practice and knowledge generation (Pretorius, 2003: 14).The first institutional arrangement is characterized by internal self-determination, where the HEI possesses institutional autonomy, independence and freedom to pursue its own agenda (Pretorius, 2003: 16). This may be evidenced in individualized, self-centered, self-indulgent academic pursuits that have little relevance to the society wherein they are located (Pretorius, 2003: 16). Subsequently, the curriculum, content and pedagogy are ratified by the university 
senate, respective faculty, schools and departments (Pretorius, 2003: 16). Thus knowledge production at these institutions is seen as ends in themselves and not beholden to society for solving social problems (Pretorius, 2003: 17), which informs an account of a dissociated , private institution wedded to a neoliberal, capitalist (private property) framework and does not inspire critical democratic pedagogy turned toward social transformation. Secondly, HEIs identified as having external determination are owned by the church, the state, commerce or a particular community (Pretorius, 2003: 17). The organizational arrangement in this case answers to an external social group who controls decisions on the university's practice and mission, making this a relationship of domination and subordination (Pretorius, 2003: 17). With limited institutional autonomy, this type of HEI serves the needs and interests of the controlling group and has to conform to the imposed ideology of the external party (Pretorius, 2003: 17). The problematic in such an arrangement with regards to critical democratic pedagogy is that the lack of autonomy and the domination from external overlords means that pedagogy too is externally influenced through a particular ideology. Thirdly, HEIs acknowledged as having limited or pseudo engagement subscribe to an underdeveloped notion of engagement and do not connect with the state or society in a reciprocal manner (Pretorius, 2003: 18). Thus, this type of HEI is committed to knowledge generation on the traditional science model, whereas they generally serve the community in a welfares, non-caring way as their primary interest is the pursuit of revenue (Pretorius, 2003: 19). In this instance, an over-reliance on positivism might shape formulaic pedagogical frameworks that see education as a closed system or process that can be learned and perfected without true qualitative interaction turned toward social change and a vibrant democracy.

Fourthly, Pretorius recognizes the "promiscuous engagement" between HEIs and society, where the focus is on information and knowledge to be used for producing market and social value (Pretorius, 2003: 19). This type of approach employs science for innovation, productivity and competitiveness in global markets (Pretorius, 2003: 19). Thus, there is no boundary between the university and society, and the production and application of knowledge may occur in a trans-disciplinary fashion as the university is accountable to diverse markets and the society; and is not obligated to peer-review for quality evaluation (Pretorius, 2003:20). Taken as such, knowledge generation is not purely guided by scientific rules, it occurs more swiftly to reduce intervals between innovation and commercialization, and it annihilates the need for lengthy abstract theoretical reflection (Pretorius, 2003: 20). This HEI and the subsequent one below (as will be revealed shortly) adhere to a strong neoliberal and functionalist concept of knowledge production and pedagogical application. Such frameworks are identified by their faith in a certain body of knowledge, rigid and de-contextualized pedagogy, and teacher- led and teacher-focused exercises of content mastery based on functional monologism. And lastly, the corporate university is owned by a corporate entity and holds no internal autonomy or integrity in knowledge generation (Pretorius, 2003: 20). This category of institution works in the interest of corporate needs and abides by corporate culture with regards to the specific requirements and mission thereof (Pretorius, 2003:20). The limitation of such engagement is grounded in the fact that such a HEI is loyal to a pedagogical model fashioned after the corporate model based on efficiency and continuity, rather than seeing democratic pedagogy as an activity that accommodates difference and diversity in a commitment to intellectual and democratic social growth (not purely economic growth). In this section I have attempted to illustrate the pedagogical implications of the hazardous neoliberal features of NCS/CAPS and the attendant classroom practices that may flow under institutional arrangements that show 
a lack of academic freedom and intellectual autonomy for HEI teachers, presenting small hope that critical democratic pedagogy can survive in such restrictive conditions. With the above in mind, I now shift our attention to classroom practices in schools to help understand whether a more socially responsive and critical democratic pedagogy might be evident.

Molteno argues that within even a mechanistic educational model, agentive students may not inevitably reproduce capitalist social relations, and that they may in fact through conscious agency contradict, struggle, and fight for self-determination (Molteno, 1987: 6). He bases this claim on his study and analysis of the student boycotts of 1980 in the Cape Peninsula where a student-initiated and student-led class struggle against racialized, poorly resourced, authoritarian education (Molteno, 1987: 3) was instituted. To begin with, localized student mobilization meant that students took control of schools by deposing adult, authoritarian management, and installing student representative councils (Molteno, 1987: 9). In this way, students were able to balance asymmetrical power relations and demand more respect and autonomy from the adults in the school. Next, as a counter-hegemonic measure, student councils organized "awareness programs" and led talks and guided discussions on socially relevant topics as noted by this student below:

We tried to get them to read their newspaper effectively, to criticize it, and not to be misled. (Molteno, 1987:10).

Additionally, in their awareness of the broader social struggles students showed solidarity with the injustice suffered by their community members in general, by actively supporting a local meat workers' strike and bus boycott as they saw their issues for social justice aligned. (Molteno, 1987: 11). And finally, the impact made by the boycott was materially marginal in the sense that the students' short term goals were met in the provisioning of books and building repairs, yet the larger, systemic, structural concerns were not addressed by the state (Molteno, 1987: 13). However, the symbolical significance of the boycott can be summed up by this student:

It was not anything that was granted by the authorities which was felt to be important but rather the spirit and what had happened amongst the people (Molteno, 1987: 14).

However, as Molteno avers, students' social resistance contributed to the mobilization and conscientization (consciousness-raising or awareness) of adults not only then, but it was antecedent to the 1984 student movements that took place in South Africa (Molteno, 1987: 16).

\section{Pedagogical encounters that might reveal critical democratic pedagogy: Grade $1 \mathrm{OBE} / \mathrm{C} 2005$ Classroom}

Almost two decades after the Cape Peninsula student boycott brings us to a researcher's observation during data collection in a Grade 1 class in 1998. What follows emanated from research field notes that were captured while collecting raw data in preparation of a report on the implementation (whether it was or was not being implemented) of OBE in 32 classes in two provinces in South Africa. The significance of this case is the teacher-student interaction that ensues provides insight into how critical democratic pedagogy might be revealed. 
She spent most of the time punishing the kids. She hits them on the forehead, on their buttocks, on their hands and bodies, for [a] not being able to read, write or do numeracy; and [b] for not erasing what they have already written.... When the teacher asks a question, the learners start shivering. Even if they are making words from cards, they are scared to show the teacher because they are scared of the punishment they will get. (Jansen, 1999: 15).

The researcher's observation reveals some shocking pedagogical practice that literally petrifies and fossilizes young children in a Grade 1 class. In this instance, the teacher has internalized the moralistic ideology of Fundamental Pedagogics and acts in an ultra-authoritarian way, much like the way the apartheid state repressed citizens through the state apparatuses of the military and the police force (SAHO, 2014). The teacher inflicts physical abuse by hitting these young children on their bodies and mid to upper extremities for actions as trivial as not erasing work. Further to this, she dehumanizes the students by brutalizing them for not being able to read, write and compute, when it could be understood that Grade 1 being an inception year, not all students may have had sufficient exposure to formal schooling to be competent in mathematics and reading yet. Whereas OBE (which it can be loosely argued, embraces and is premised upon elements of critical pedagogy) calls for group work, self-learning, learnercentered instruction, activity-based learning, learning by discovery, less direct teaching and more teacher facilitation, less of a focus on content coverage, learning by doing etc. (Jansen, 1999: 8); the teacher in the above example defies all conditions for any fruitful pedagogic engagement. She has stultified the young students to the point where it seems implausible that any activity based learning, discovery learning or learner-centered instruction can survive. In this situation, the teacher's violence and ability to instil paralyzing fear in the students has foreclosed on any attempt at meaningful direct teaching and teacher facilitation, to the point that one is inclined even to welcome more content coverage in place of "spending most of the time punishing the kids". The teacher actions are objectionable and reprehensible as she uses her physical and chronological age advantage, as well as her professional (authoritarian) position to inhibit and immobilize student agency to the point where students dare not take risks, discover, create, and be active in their own learning. The example presented exhibits extreme inequality in providing an optimally safe and compassionate pedagogic encounter, and transgresses the most basic premise of democracy: freedom and justice. Ultimately, the teacher in this scenario can be described as an oppressor according to Freire, as she seeks to dehumanize by reserving humanity for herself and in a parallel manoeuvre to reserve teaching and learning for herself, as she incarcerates students with violence and fear (Freire, 2005:2044). Not only does she transgress the conditions of basic democracy and the guidelines of $\mathrm{OBE} / \mathrm{C} 2005$, but more importantly she contravenes the right to human dignity as enshrined in the constitution (Constitution of SA, 1997: Ch2, section 10).

\section{Pedagogical encounters that might reveal critical democratic pedagogy: Complex classroom encounters (Evans \& Cleghorn, 2012)}

The rationale of this study, as described by the researchers, was to understand the nature and complexity of language encounters in diverse instructional settings (Evans \& Cleghorn, 2012: xvi). Set within a conceptual framework of language-in-education, the multi-literacies study focused on Foundation Phase pedagogic encounters between January 2008 and October 2011 in two English medium schools in Gauteng (Evans \& Cleghorn, 2012: xvi). Methodologically, 
the study is conceived from a reflective ethnographic and sociolinguistic perspective, while being interpretive and critical in approach (Evans \& Cleghorn, 2012: xvi). Data collection was carried out via classroom-based observation in order to juxtapose the "language issue" in South African as representative of abstractions such as official policy, apartheid legacy, the inequality between rural and urban achievement (Evans \& Cleghorn, 2012: xvi) versus authentic classroom pedagogy. In its turn, the study sought to demystify language encounters by highlighting the social and pedagogical implications of how learners are being taught with a view to develop appropriate curricula for teacher training (Evans \& Cleghorn, 2012: xvi). The authors interpret the philosophy of official education policy as "guiding learners towards democratic citizenship" (Evans \& Cleghorn, 2012: xvi). And such:

transformative pedagogy places the rights of the learner at centre and demands a reflective, critical approach from the teacher, an approach that is highly dependent on extensive training, usually to the Masters level or beyond (Evans \& Cleghorn, 2012: 29).

However, pedagogic engagements revealed that teachers relied on the "banking method" of education while they set behavioral prescriptions that were linguistically difficult to understand, and conceptually and culturally unfamiliar and strange to students (Evans \& Cleghorn, 2012: 30).

According to Evans \& Cleghorn, three themes emerged from the interview and observational data viz. educational philosophies with a focus on control in the guise of discipline and obedience; the emphasis on Western education and the concomitant cultural tensions it wrought within the classroom; and lastly the apartheid era and post-apartheid realities as seen in trying to overcome the teacher-centered pedagogical approach (Evans \& Cleghorn, 2012: 31). As it relates to the theme of control, the authors propose that teachers were not prepared for the diversity of learners and were preoccupied with control through discipline, as is evident in this teacher interview:

The pride that I am talking about is, you know, having children that are disciplined, that you can control ... and now things are a bit problematic and then I do not think that we are going to get the discipline part of it back to where it was because our Government has introduced "children's rights". Now it seems like the children and the parents, they are more on the rights side of the children and not the responsibilities that go hand and hand with that (Evans \& Cleghorn, 2012: 31).

In that regard, what follows below is the testimony of a student intern who herself was educated in a township school:

When I was in grade 1 there was still corporal punishment so they either shouted at you or hit you. ... all these years I thought the only way that children would listen to you is if you shout at them or hit them, but then when I went to [school's name] I noticed that ... that's not even necessary. Now I cannot even imagine myself hitting a child. ... Be calm, speak to them like a little adult, I think they respect you more when you speak to them like a person who thinks, a person who has an opinion, and not be in control all the time (Evans \& Cleghorn, 2012: 32). 
Miss K noted the lack of opportunity for oral practice and interaction between the learners during language lessons (Evans \& Cleghorn, 2012: 35):

No, it's not given, [the opportunity to talk with each other]. Immediately they start talking and the teachers say; "You are making noise, Why are you not listening to me"? The teacher is not even waiting for the answer. "Why are you doing this, why are you playing with your friends? Focus sister, listen to me. I asked you a question, answer me". At the end of the day they did not learn anything or they did not understand the content of what she was trying to teach them (Evans \& Cleghorn, 2012: 35).

Consequently, the three scenarios illustrated above reveal that official educational policies and statements should be defined less and less by their legal frameworks and should rather be considered by how they bear meaning in classroom pedagogic encounters. With the above in mind, I plan to demonstrate how the abstraction of curriculum discourse collides with the learning engagements in college and school classroom.

Giroux (2011) contends that higher education institutions and schools could correctly be seen as repressive institutions in the way that teacher, and most importantly, student agency and freedom are compromised. He relates his theory directly to marginal students (as in the case of the language-in-education students mentioned above) and the inability of teachers to provide access to a critical language (Giroux, 2011). Instead, teachers are guilty of transgressing many ethical and political dimensions in their pedagogic practice since they themselves are impacted by many external ontological and epistemological registers (Giroux, 2011). Additionally, as Evans and Cleghorn have highlighted, there exists the deep necessity to develop appropriate curricula for teacher training, since teaching (at college and school level) is impacted by institutional culture (see Pretorius, 2003) and is directed by academics that are out of touch with the everyday culture of under-resourced students (Giroux, 2011). This dissociation from the lived reality of students reinforces the classist nature of schooling and entrenches a situation where elite cultural capital is normalized. As a result, critical democratic pedagogy in the form of radical education turned toward transformation and social justice is severely hamstrung. To this Giroux proposes that curricula be developed that provide a more expansive and democratic politics (see Shor above), removed from the practice of academics who could easily be labelled "uptight, politically conservative, personally arrogant"; and who are given to "pompous self-flattery, display a haughty indifference to human suffering and are divorced from pressing social issues" (Giroux, 2011, Pretorius, 2003:17). Furthermore, he reveals his own self-interest and claims that his origins as a non-elite student, provides him with the sensitivity to recognize non-dominant class positions (and those traditionally excluded from the academy), and the theoretical and practical insight of how to navigate this difficult class experience more successfully. These sensibilities and responsiveness to a critical democratic pedagogy transgress the neoliberal conventions that widen the gap in education in terms of economic inequality, access, as well as the promotion of an elite culture that excludes the histories, experiences, language and cultural backgrounds of working-class students (Giroux, 2011). For example, what could be considered an unproblematic demand in education is academic achievement and success, yet what gets obscured is that working-class students compete with elite students who have better resources (time, cultural capital, language) and have been better prepared for school culture (Giroux, 2011). It is imagined that democratic action in such an instance could be seen in the form of relentless critique and dialogue of 
official power, yet universities have a notorious habit of silencing dissent, foreclosing on any defensible vestige of democratic practice focused on the common good (Giroux, 2011). In this case, Giroux and Pretorius' theories coincide: knowledge becomes "commodified" in an "audit culture" where corporate values and interests; economic rationality and mathematical utility translate to national prosperity and economic growth (Giroux, 2011, Pretorius, 2003). The danger herein lay in the fact that technical innovation and market transformation do not alleviate social suffering (inequality, poverty, crime, homelessness etc.) as pledged and guaranteed in liberal democracy (Giroux, 2011). And the failure of teachers to engage with socially relevant topics, disallow students to engage in "democratic dreaming"; which simply means the social investment in critical dialogue that imagines another world outside of unbridled capital. It is in a state where alternatives are sought that student and teacher agency could be considered autonomous and critical; open to taking risks; and engaged in thoughtful dialogue for socially responsible action (Giroux, 2011). However, the cultural apparatus of the curriculum and its institutions disconnect education from critical thought to the degree that students are seen as consumers (of a product called technical knowledge) wherein new desires, needs, modes of identity and social relations should be mobilized (Giroux, 2011). Thus, an authoritarian, disciplinary culture pervades schooling to guard against the production of critical (as seen in critical pedagogy) knowledge, and to resist democratic modes of agency that take the responsibilities and obligations of citizenship seriously by engaging in public issues rather than merely enjoying private life (Giroux, 2011). Giroux confronts teachers with their responsibilities as public intellectuals to provide the template for students to engage in public scholarship that is rigorous and dialectical so as to inspire and develop new modes of civic agency where power is connected to action; and where the social relevance of knowledge and individual rights are not unhinged from social rights (and duties). Now that I have attempted to unpack pedagogical encounters that might reveal critical democratic pedagogy, as well as the theoretical frameworks that define critical democratic pedagogy, I transition into a discussion below of the implications all of this has for advancing a more socially defensible account of schooling.

\section{Critical democratic pedagogy challenges the correspondence principle}

Bowles and Gintis" “correspondence principle” (Bowles \& Gintis, 1976: 246) suggests at the social reproduction function of schooling that coincides with the capitalist economic structure, by entrenching inequality while creating the popular fiction of social mobility through meritocracy (Molteno, 1987:4). Consequently, capitalist structures reproduce social relations and structures that favor the dominant elite; while accommodating a mechanistic model (as seen through education) of supplying cheap labor for capital (Molteno, 1987:10). In this way schools and HEIs reflect the productive cycle where students (groomed to be workers) learn to be silenced, accept orders, obey institutional hierarchy and develop an unhealthy dependence on external authority to shape their reality. This approach to education closes off opportunities for students to consciously reflect and criticize anti-democratic behavior and inhibits pedagogical engagement premised on dialogical, co-intentional, co-equal problemposing pedagogy. Instead, controlling pedagogy as advocated in CNE/FP seems to predominate classroom encounters as seen above in the research of Evans and Cleghorn, (2012) and Jansen (1999). And while OBE/C2005 and NCS/CAPS are considered progressive and critical curriculum plans, the latter does not escape the undesirable elements of a neoliberal discourse 
which undermines critical democratic pedagogy. On the basis, that neoliberalism favors social hierarchy predicated on classism, privatization, commercialism and market - driven technical rationality; the danger presented by a neoliberal mentality in education spells further anti-democratic action in schools. This is borne out by the fact that students and teachers are more likely to face oppression, inequality, and deskilling to meet the demands of capitalist logic, which prizes scientific knowledge for a skilled labor force, and a functionalist mentality that controls students and teachers to follow directions, respect authority and avoid critical questions. In the light of the above, Shor's theorizing of critical democratic pedagogy has not been strongly evidenced in the classroom engagements previously highlighted, to help us determine how democratic South African classrooms are. While Shor envisions a democratic pedagogy to revolve around power-sharing, shared authority, co-governance and curriculum negotiation, only two cases come remotely close to democratic interaction. In the first case (the Cape Peninsula student boycott), I would like to venture the merits of the case are more profoundly an exhibition of critical student agency than democratic pedagogy. By virtue of the fact that students seize control of the pedagogic situation and enact self-motivated, selforganizing democratic action by challenging unequal power and transforming social reality, it could not be considered pedagogic power-sharing since teacher agency seems immobilized. In the second case, a trainee teacher critically reflects on undemocratic pedagogy by way of teacher authoritarian violence. Her abhorrence for this deplorable and abusive control, creates the promise of a fissure for her to adopt a more dialogical, co-equal and humane practice that is transformational and will allow students to develop to their full human potentiality as thinking beings. With the exception of these two cases, the rest of the encounters display the "discipline and control" (in the teacher's own words) of unequal power and domination with regards to teacher behaviors, and the severe silencing of student voice. In one particular case, the teacher even problematizes the constitutional rights of students and parents; which implies that only she should be given power to exercise her rights, albeit that she sees these rights as central to protect her ability to exercise power over students and parents; as well her right to enforce order, restraint and punishment on students with impunity. In sum, teacher agency in university and schools seems to indicate a democratically deficient pedagogy closely modeled against the capitalist unidirectional current of authoritarian hierarchy which mirrors: the classist nature of capitalism (where elites dominate the superstructure); the chain of command in corporations (where the owner/boss governs and supervises the worker); and lastly the classroom where the teacher exercises power over younger students.

\section{Conclusion}

While critical democratic pedagogy seems like an enticing alternative educational practice that has been carried out successfully in other contexts, it has not truly been given much recognition in South African education. Taken in the light of a checkered and repressive educational past, one would imagine that critical democratic pedagogy would be embraced and allowed to flourish in South African education simply because the nation theoretically has one of the best-articulated constitutions, and two of the most recent curriculum statements are consonant with critical pedagogy. Having said the above, it however cannot simply be anticipated that decades of anti-democratic teaching and learning will be erased without a concerted effort in teacher training to usher in transformational, dialogical, democratic pedagogy. And if Giroux is to be taken seriously that education holds no guarantees since 
(social) justice is never complete, and that democracy is never fully settled (Giroux, 2011), we can be inspired that the new age in South African education has only begun. Thus, the infancy of this new dawning is the opportune horizon whereupon alternative, experimental, transformational and democratic educational practices need to be highlighted and tested in order to develop new modes of agency, power and action.

\section{References}

Chisholm, Linda. A South African Curriculum reform the twenty first century. Pretoria, 2002.

Department of Higher Education and Training, DHET. Integrated Strategic Planning Framework for Teacher Education and Development in South Africa, 2011-2025, 2011.

Eshak, Yousuf Ishmail. Authority In Christian National Education and Fundamental Pedagogics. Johannesburg: University of the Witwatersrand, 1987.

Freire, Paulo. Pedagogy of the oppressed. New rev. 30th-Anniversary ed. New York: Continuum: Continuum, 2005.

Giroux, Henry. Henry Giroux on Democracy Unsettled: From Critical Pedagogy to the War on Youth. (M. Peters, Interviewer), 2011, August 29.

Isaacs, Tracey. Imagining Critical Cosmic Pedagogy nested within Critical Pedagogy. Philosophy and Cosmology, Volume 14, 2015: 162-173.

Jansen, Jonathan. Noisy OBE. Durban: University of Durban-Westville, 1999.

Kincheloe, Joel, and Steinberg, Shirley, R. What you don't know about schools. In $J$. \&. Kincheloe, What you don't know about schools. New York: Palgrave MacMillan, 2006:1-16

Leibowitz, Brenda. Lessons for policy makers from retrospective accounts of schooling in South Africa . International Literacy Conference. Cape Town: The University of Cape Town, 2001.

Lombard, Kobus, and Grosser, Mary. Critical thinking abilities among prospective educators: ideals versus realities. South African Journal of Education, 2004: 212-216.

Molteno, Frank. Students Take Control: The 1980 Boycott of Coloured Education in the Cape Peninsula. British Journal of Sociology of Education, Vol. 8, No. 1 ,1987: 3-22.

Naicker, Sigamoney Manicka. From apartheid education to inclusive education: The challenges of transformation. International education summit For a Democratic Society . Michigan: Wayne State University, 2000.

Pretorius, Deon. A Tale of Three Countries:Social Sciences CurriculumTransformations in Southern Africa. Lansdowne: Juta \& Co Pty Ltd, 2003.

Shor. Ira. When Students Have Power. Chicago and London: University of Chicago Press, 1996. 